https://helda.helsinki.fi

\title{
Exploration of individual study paths of successful first-year students : an interview study
}

\section{Lindblom-Ylänne, Sari}

$2017-10$

Lindblom-Ylänne , S , Haarala-Muhonen , A , Postareff , L \& Hailikari , T 2017 , ' Exploration

of individual study paths of successful first-year students : an interview study ' , European

Journal of Psychology of Education , vol. 32 , no. 4 , pp. 687-701 . https://doi.org/10.1007/s10212-016-0315-8

http://hdl.handle.net/10138/308519

https://doi.org/10.1007/s10212-016-0315-8

unspecified

acceptedVersion

Downloaded from Helda, University of Helsinki institutional repository.

This is an electronic reprint of the original article.

This reprint may differ from the original in pagination and typographic detail.

Please cite the original version. 
Exploration of individual study paths of successful first-year students: an interview study

Sari Lindblom-Ylänne ${ }^{1}$, Anne Haarala-Muhonen ${ }^{2}$, Liisa Postareff ${ }^{1} \&$ Telle Hailikari $^{1}$

${ }^{1}$ Faculty of Behavioural Sciences, University of Helsinki, Finland

${ }^{2}$ Faculty of Law, University of Helsinki, Finland

European Journal of Psychology of Education

Corresponding author:

Sari Lindblom-Ylänne

Sari.lindblom@helsinki.fi

Phone +358400846672 


\section{Abstract}

The aim of the present study was to explore the individual profiles of successful, rapidly progressing first-year university students. The participants numbered 38 humanities and law students, who volunteered to be interviewed. The interview data were analysed using abductive content analysis. Two student profiles were distinguished: Strenuously progressing students, who were interested and motivated but had to work hard to meet their deadlines and maintain a rapid study pace (applying a defensive pessimism cognitive strategy), and Effortlessly progressing students, who had very good self-regulation skills, strong self-efficacy for self-regulation and the most positive experiences of their learning environment. These students applied a deep approach to learning and an optimistic cognitive strategy. The results highlight the complex interplay between motivational and volitional factors, the approaches to learning, and the cognitive attributional strategies affecting individual study paths.

Keywords: successful studying, cognitive-attributional strategies, self-regulation, self-efficacy beliefs, motivation to study, approaches to learning

\section{Introduction}

In many European universities, students' graduation times are longer than the expected $3+2$ years for the completion of Bachelor's and Master's degrees. At the same time, authorities are 
posing increasing demands on universities to shorten graduation times, allowing students to enter the labour market as soon as possible. In Finland, prolonged study time is a particular challenge in the humanities, where students take more time to complete their degrees compared to other academic domains. However, the problem is not only a Finnish one, as universities internationally are also having to increasingly monitor their students' progress. From this point of view, it is important to explore the individual factors that contribute to successful studying and rapid study progress in order to better support students as they endeavour to study successfully and graduate in a timely manner.

Researchers have a good overall picture of what constitutes successful studying at university. Ample empirical evidence shows that successful studying and study progress are affected by students' motivation and their interest in studying, as well as their metacognitive and self-regulation skills (e.g. Entwistle 2009; Heikkilä et al. 2012; Parpala et al. 2010; Pintrich 2004). Interest in studying is pivotal, as it leads to good academic results (e.g. Hidi and Renninger 2006; Krapp 2002; 2005; Mikkonen et al. 2009). Intrinsic motivation to study is also a key contributing factor in the completion of degrees (e.g. Dewitte and Lens 2000; Mikkonen and Ruohoniemi 2011), along with strong self-efficacy beliefs (e.g. Cheng and Chiou 2010). Further, maintaining a volitional mind-set, that is, an orientation toward attaining a chosen goal, is important (Dewitte and Lens 2000). Universities expect students to be responsible for their own learning and to regulate and monitor their learning processes (e.g. Lindblom-Ylänne 2004). However, self-regulation and time management can be challenging for many students as they struggle in learning environments that call for independent studying (e.g. LindblomYlänne 2004). A lack of self-regulation and time-management skills can hinder the progress of studies and increase students' study-related problems (Vermunt 2005; Heikkilä et al. 2012). Klassen, Krawschuk and Rajani (2008) interestingly showed that self-efficacy for selfregulation, meaning an individual's beliefs in his or her ability to use a variety of learning 
strategies, resist distractions, complete schoolwork, and participate in class, promotes academic success.

Although several studies have shown that a deep approach to learning increases the likelihood of academic progress (Duff 2004; Lindblom-Ylänne and Lonka 1999) and optimal learning outcomes (e.g. Amirali et al. 2004; Román et al. 2008), others have found no link between a deep approach and study success. Students applying a deep approach aim at understanding and constructing meaning from the study material/ content by integrating new information with previous knowledge, using evidence, and by critical thinking (Marton and Säljö 1997; Entwistle and Ramsden 1983; Entwistle 2009). A surface approach to learning, on the other hand, focuses more on memorising without aiming at understanding, which often results in fragmented knowledge structures (Entwistle and McCune 2004). A third approach to learning, labelled organised studying and effort management, refers to the ability to manage time and effort (Entwistle and McCune 2004), and is closely related to self-regulation. Evidence is contradictory concerning the relationship between these approaches to learning and study success. Some studies show that a deep approach improves learning outcomes (e.g. Biggs 1979; Entwistle and Ramsden 1983; Lindblom-Ylänne and Lonka 1999; Trigwell et al. 2012), whereas others find no evidence of this, perhaps because course grades do not necessarily reflect the quality of learning outcomes in a reliable manner (e.g. Asikainen et al. 2013; Segers et al. 2003; Struyven et al. 2005). Rytkönen et al. (2012) found study success and academic progression to be strongly associated with the use of organised studying and effort management. In addition, cognitive attributional strategies are also related to study progress and success at university (e.g. Eronen et al. 1998; Heikkilä and Lonka 2006; Heikkilä et al. 2012; Martin et al. 2003; Nurmi et al. 2003). These strategies describe how students deal with their studies and study-related threats to self-esteem (e.g. Eronen et al. 1998; Heikkilä et al. 2012). Students who employ an optimistic task-focused strategy and active coping when faced with challenging goals 
succeed well at university (e.g Heikkilä et al. 2012; Nurmi et al.2003). Self-efficacy beliefs seem to have a mediating role in how challenging situations are experienced. Students with strong self-efficacy beliefs do not experience such situations to be threatening in the way students with low self-efficacy beliefs do (Meijen et al. 2013). On the other hand, those who deliberatively avoid challenging goals employ a self-handicapping strategy in which avoiding effort is a way to make good performance less likely and to protect one's sense of self-competence (Heikkilä et al. 2012; Jones and Berglas 1978; Martin et al. 2003; Nurmi et al. 2003). Furthermore, typical of a self-handicapping strategy is maladaptive task-irrelevant behaviour and a preference for external regulation where responsibility for the learning process is shifted to the teacher (Heikkilä and Lonka 2006). Finally, students who employ a defensive pessimism strategy set low expectations in challenging situations in order to motivate themselves to work hard and prevent failure (e.g. Cantor and Norem 1989; Martin et al. 2003; Norem and Cantor 1986). A defensive pessimism cognitive strategy has been shown to be an effective way to motivate students to improve performance and cope with study-related stress (Martin et al.2003; Cantor and Norem 1989). With a defensive pessimism strategy, students cope with anxiety by using it to motivate themselves (Norem and Cantor 1986).

\section{Aims of the study}

The study aims to explore Bachelor's students' individual study profiles during the first year at university. From the point of view of study progress, the first year is particularly decisive for students' future development and success at university (e.g. Gale and Parker 2014). Despite the good overall picture of the factors contributing to successful studying, we still lack an understanding of those that enhance the progress of university students at the individual level. Our assumption is that even though this rapidly progressing group of first-year students seems 
homogeneous in nature at the group level in terms of their study progress and success, there is individual variation regarding the students' motivation and interest in studying, approaches to learning, self-efficacy beliefs, self-regulation skills and in how their use of cognitive attributional strategies explains success and failure.

We focus on investigating a group of students whose progress has been faster and success better than those of average students. The study is an extension of our earlier research where we explored the slow study progress of university students (Authors 2015a). We chose a person-oriented qualitative approach in order to gain a deeper understanding of the factors related to and explaining rapid study progress among first-year university students, feeling that such an approach could shed more light on the students' individual study profiles.

\section{Method}

\subsection{Participants}

The participants comprised 38 first-year Bachelor-level humanities and law students (24 and 14, respectively), from a research-intensive university, whose study pace had been the fastest in their programmes. We had first applied purposive sampling and invited students who had earned more than the required 60 credits to participate in interviews after their first university year. The level of participation was high, at 73\%. Study success measured by the students' GPA was above average: 3.3 (i.e. between "good" and "very good") of a maximum of 5.0 in both humanities and law.

The average age of the students was 23 years. Altogether $21 \%$ of the humanities and $64 \%$ of the law students were male. Interestingly, male students were slightly under-represented in 
the humanities sample, their proportion of the cohort being $23 \%$, but over-represented in the law sample, their proportion being $43 \%$.

These two disciplines were selected because the Bachelor's degree graduation times for humanities students are on average the longest and for law students the shortest. In addition, the two Bachelor's curricula are different in nature: the law curriculum is professional, comprised mainly of law studies with few optional courses, whereas humanities students can freely choose their minors and there are fewer compulsory elements.

\subsection{Materials}

The participants volunteered to be interviewed after their first study year. The data collection was approved by the faculties. The students were informed that the results of the study would be used to enhance the programme design and development of the teaching-learning environments to better support individual students' needs. The students gave their informed consent to participate in the study and were told that they could withdraw from it at any time. The interviews concentrated on factors that according to previous research have been shown to enhance study progress and successful studying. We did not specifically ask for the students' views or explanations of their fast study pace. Instead, the interviews focused on the students' aims, study processes, as well as experiences and evaluations of their first study year. By doing so, we wanted to ensure that the students' spontaneous and personal views were heard, and that our questions did not steer the students to look at their first study year specifically from the point of view of their progress and success.

The second and fourth authors acted as interviewers; the second author interviewed the law students and the fourth the humanities students. The length of the interviews varied from approximately forty minutes to an hour, and the interviews were transcribed verbatim. The 
selected extracts were translated into English, and, due to the translation process, do not represent authentic spoken English. To ensure the anonymity of the interviewees, the age and gender of the participants are not revealed. All students are referred to as 'she'. In the Results section, the humanities students are referred to as $\mathrm{H}$, and law students as $\mathrm{L}$.

\subsection{Procedure}

The data were analysed using abductive content analysis (Timmermans and Tavory 2012). Abduction refers here to producing an explanatory hypothesis as well as to introducing new ideas. Abductive reasoning is a process that combines elements of a phenomenon that have not been previously associated, by creating a new interpretation of the phenomenon. In an abductive analysis the themes identified from the data are linked to the theoretical understanding based on previous studies. According to Timmermans and Tavory $(2012,174)$, "abductive analysis specifically aims at generating novel theoretical insights that reframe empirical findings in contrast to existing theories". Abductive analysis aims at identifying changed circumstances, additional dimensions or misguided preconceptions through exploring and reflecting on the data in the light of existing theoretical models. Therefore, "abductive analysis [ ] rests for a large part on the scope and sophistication of the theoretical background a researcher brings to research" (Timmermans and Tavory 2012,173).

The present study's abductive analysis involved a cyclical process of moving forward and back within the data and understanding the phenomenon based on prior studies. This "recursive process of double-fitting data and theories" (Timmermans and Tavory 2012,179) requires many lenses. Therefore, all four authors participated in the analysis process. The process consisted of two phases. In the first, each interview transcript was analysed independently by the authors in a cycle of four rounds. Each round focused on an important 
theme which has been shown by previous research to explain and predict study success and progress:

1) intrinsic motivation, interest in studying, volitional mind-set and strong self-efficacy beliefs;

2) self-regulation and self-efficacy for self-regulation;

3) application of a deep approach to learning;

4) an optimistic task-focused cognitive strategy and active coping, or a defensive pessimism cognitive strategy, and no self-handicapping strategy.

During each round the data were reflected on in the light of existing theoretical models and empirical evidence. After each round, the authors independently explored how well the previous theoretical models were reflected in the data. At the end of the first phase the authors compared their analysis results to see how well the selected theoretical models fit the data, and, further, to create a synthesis of the variation found in the four themes. The comparisons showed high agreement among the authors.

The second phase focused on creating the student profiles on the basis of the variation found in the four themes. The 38 students were analysed one-by-one using the four abovementioned themes. Two student profiles clearly emerged from the data. The authors were unanimous when categorising the students into the two profiles, except for one student who the authors found difficult to categorise and was given a separate profile.

\section{Results}

The study aimed at exploring the individual study paths of rapidly progressing university students. Our assumption was that even though this rapidly progressing group of first-year students seemed homogeneous in nature at the group level, individual variation could be 
identified in these students' study practices, processes and experiences. This assumption was partly supported. On the one hand, we found little variation in students' intrinsic motivation, interest in studying, self-efficacy beliefs and volitional mind-sets. On the other, we detected variation in the students' use of a deep approach to learning, in their time-management and self-regulation skills, and in their cognitive attributional strategies. On the basis of the identified variation, two student profiles emerged: Effortlessly progressing students $(\mathrm{n}=26,68 \%)$ and Strenuously progressing students (n=11,29\%) (For a summary, see Table 1). All students had passed all exams of their first study year, but one student had missed some deadlines for assignments. This particular student was not categorised into either of the profiles determined from the data because her individual profile was too different.

Effortlessly progressing students

The profile for Effortlessly progressing students consisted of 14 humanities and 12 law students. All were highly motivated to study and interested in their disciplines, as the following extract shows:

One of the most important enhancing factors is my love of law. I have liked it immensely. Having an object of love has been 'the thing'. (Student L12)

These students all showed strong self-efficacy beliefs concerning their academic success, and a volitional mind-set as well, because they had set themselves personal goals and strived toward attaining them, as the following typical extract shows:

Of course [my goal was] to be able to complete all courses I planned to take, so that there would be no unfinished tasks or courses. I aimed at completing 60 credits per year. I wanted to stick to my original study plan. So I followed that plan. (Student H29) 
Effortlessly progressing students had very good self-regulation and time-management skills, and had tailored their skills to fit their objectives and personal preferences:

I mark my study times for each exam on my calendar. I have learned how much time I need to study different subjects. I make exact plans separately for each term (Student L18). Interestingly, all except two students had worked at least part time during the academic year without it affecting their studies. Combining full-time successful studying with part-time work demonstrates good self-regulation and time-management skills, as the following extract shows:

I'm very good at time management. I work part time and therefore I carefully plan my study time. I have decided to really concentrate on what I'm reading, so I don't need repetition. As funny as it sounds, working part time helps me to do my best. I don't think I could have achieved more by stopping work. (Student L15)

Effortlessly progressing students showed strong self-efficacy for self-regulation. For example, they expressed strong confidence in themselves being able to plan and monitor the learning process as well as being able to reach their goals:

I think I'm a master of project management [laughs]. Well maybe not a master, but I can always complete what I intend to do, and I use quite a lot of time for planning and time management, like what to do when and what courses to take. It's important because this way I avoid a too heavy workload. Sometimes it's difficult to evaluate how much time a course really takes, because the number of credits doesn't always tell the real amount of work needed to complete a course. (Student H36)

These students were also able to control and regulate their motivation to study:

It wasn't difficult at all, everything went really easy. I was surprised. I had a couple of courses that I wasn't much interested in, but it's important to keep yourself motivated all the time. (Student H18) 
All students in this profile systematically applied a deep approach to learning. They emphasised the importance of understanding and creating meaning, as these two typical extracts show: I'm not studying just to graduate, I really want to learn and understand things. I'm studying for my future: to learn and understand, and to be able to apply my knowledge in the future, not just to pass exams. (Student H18)

Most important for me is to integrate new knowledge into my worldview, into a broader picture. Studying is not just for remembering facts, it’s for growing as a person. In my opinion, one's own thinking is very important. It's the only way to learn well. (Student H26) The typical characteristics of an optimistic strategy were clearly visible in this profile. Effortlessly progressing students had not experienced a high workload or stress, were optimistic about their studies and study success, and had very positive study experiences. The study progress of these students had been very easy and 'smooth'. All mentioned that their first university year had been easier than expected, and that they had achieved more than they anticipated. These students' study experiences were the most positive. They expressed enjoyment and pleasure in being able to study a field that was important to them. The interviews reflected a kind of lightness' in terms of studying and being a university student:

I expected studying at university to be tough and also that I might not always be enthusiastic about attending lectures, but neither has happened yet [laughs]. It's been really nice; this feels like my thing. I did not enjoy high school, and therefore did not expect to be so highly motivated, but I guess this can happen when you find your own thing. What you learn here totally depends on what you do yourself. This kind of independence is really nice - you are really responsible for your own studies and for becoming an expert in your own field. (Student H22)

Strenuously progressing students 
Strenuously progressing students comprised nine humanities and two law students. These students were as equally motivated and interested in their disciplines, and showed as strong self-efficacy beliefs and as volitional a mind-set, as Effortlessly progressing students. However, Strenuously progressing students' study progress lacked the 'lightness' of the Effortlessly progressing students. Instead, they had worked hard to self-regulate their learning processes in order to meet deadlines and to maintain their fast study pace:

Factors that enhance my progress are self-knowledge, motivation and self-discipline. I force myself to do things. Peer support also helps a lot. (Student L20)

Even though these students had not missed deadlines, many felt that time management was a challenge:

I'm the kind of student who always does everything at the last minute. Even though I might plan at the beginning of a course that this time I will start earlier, somehow I always end up doing things at the last minute. Well, maybe not the last minute, because I never miss deadlines. I always evaluate the amount of work needed. So if it's a bigger assignment, then I of course start earlier. (Student H24)

Strenuously progressing students applied a deep approach to learning as did Effortlessly progressing students, but not as systematically. Typical of Strenuously progressing students was that they varied in their approach to learning in terms of how interested and motivated they were in the content, and how much time they allocated for a specific assignment. The teaching and learning methods also affected these students' approaches to learning. Thus, they aimed at understanding and constructing meaning, and also succeeded in applying a deep approach, but not always:

My ultimate aim is to become better educated and deepen my understanding of my field, but I need to learn to use new study techniques. I'm not yet very good in applying them. I 
know in principle how I should study, but I still need to use new techniques systematically. (Student H35)

A majority of Strenuously progressing students had experienced some degree of stress or heavy workload, but some preferred to concentrate on their work more as the deadlines approached: I like my study habits. People always say that you need to study constantly and divide the workload evenly, but I prefer to concentrate on my studying just before the deadline, because I feel that I learn and remember things better that way. (Student H20).

Those who had experienced some degree of stress or heavy workload emphasised that their stress was not overwhelming, as the following extract shows:

Toward the end of each term I always get a little stressed, because I realise that I have a million things to do. The thing is that you yourself have to take responsibility. There is no one to push you forward; it's up to you. It's kind of a time-management problem, but everything has gone surprisingly well. All assignment work seems to be concentrated in a short time period and that brings stress, but it's always very short term. This happens because I'm interesting in everything. I feel like I'm in a candy store and it's very difficult to take just some, because I want so much. (Student H32)

Despite experiencing stress, these students showed a strong volition to achieve their academic goals. The independent nature of university studying and time management were seen as difficult. A volitional mind-set combined with stress or heavy workload indicates a defensive pessimism cognitive strategy. Despite using this strategy, the study experiences of Strenuously progressing students were very positive:

Well, there is the doubt that I can manage with the assignments. I usually do the assignment on the last night, and then the pressure hits me and I start doubting whether I'm able to finish it. But so far I've always coped. I just need to start earlier. It's up to me, not up to the teachers. (Student H30) 
All except one student were easily categorised into the two progress profiles described above (for a summary, see Table 1). This student had earned many credits and had progressed quickly, which was characteristic of the two progress profiles. Her fast study pace was furthermore accompanied by mild stress, which was typical of Strenuously progressing students. However, we could not categorise her into that profile, for example, because she had missed deadlines. She had also decided to work and travel for a significant amount of time during the academic year, in other words, had prioritised working and traveling over studying. In addition, the student showed weaker volition than the other students and relied on external regulation, more precisely, on a teacher monitoring her learning progress, and considered the teacher-set deadlines as crucial for her study progress. In the following extract she explains her dilatory behaviour:

I have concentration problems which delay my studying. I have a big problem with delaying studying. Really bad. When I need to study, I start getting stressed and do everything else but study so that I miss deadlines. However, I get the assignments done, late, but done anyway. When I'm stressed, it's difficult to remain motivated and to concentrate on studying. (Student H21)

Table 1. Comparison of individual student profiles in the light of motivational aspects, selfregulation, approaches to learning and cognitive attributional strategies $(\mathrm{N}=38)$.

\begin{tabular}{l|l|l|l}
\hline Theme & $\begin{array}{l}\text { Effortlessly } \\
\text { progressing students } \\
(\mathrm{n}=26)\end{array}$ & $\begin{array}{l}\text { Strenuously } \\
\text { progressing students } \\
(\mathrm{n}=11)\end{array}$ & $\begin{array}{l}\text { Unnecessarily } \\
\text { delaying student } \\
(\mathrm{n}=1)\end{array}$ \\
\hline $\begin{array}{l}\text { THEME 1 MOTIVATIONAL } \\
\text { AND VOLITIONAL } \\
\text { ASPECTS }\end{array}$ & \multicolumn{2}{l}{} \\
\hline Intrinsic motivation & very high & very high & very high \\
\hline Interest in studying & very high & very high & very high \\
\hline
\end{tabular}




\begin{tabular}{|c|c|c|c|}
\hline Self-efficacy beliefs & strong & strong & average \\
\hline Volitional mind-set & very strong & very strong & average \\
\hline \multicolumn{4}{|l|}{ THEME 2 SELF- } \\
\hline \multicolumn{4}{|l|}{ REGULATIONAND SELF- } \\
\hline \multicolumn{4}{|l|}{ EFFICACY FOR SELF- } \\
\hline \multicolumn{4}{|l|}{ REGULATION } \\
\hline Self-regulation & very good & good & average \\
\hline $\begin{array}{l}\text { Self-efficacy for self- } \\
\text { regulation }\end{array}$ & very strong & average to strong & average \\
\hline \multicolumn{4}{|l|}{ THEME 3 DEEP } \\
\hline $\begin{array}{l}\text { Using a deep approach to } \\
\text { learning }\end{array}$ & systematically & systematically & systematically \\
\hline $\begin{array}{l}\text { THEME } 4 \text { COGNITIVE } \\
\text { ATTRIBUTIONAL } \\
\text { STRATEGIES }\end{array}$ & & & \\
\hline Optimistic strategy & yes & no & no \\
\hline $\begin{array}{l}\text { Defensive pessimism } \\
\text { strategy }\end{array}$ & no & yes & yes \\
\hline $\begin{array}{l}\text { Self-handicapping } \\
\text { strategy }\end{array}$ & no & no & no \\
\hline OTHER: Study experiences & the most positive & very positive & quite positive \\
\hline
\end{tabular}

In addition, we found interesting differences between the two study environments, in other words, between the more 'professional' law and more 'open' humanities curricula. Almost all rapidly progressing law students (86\%) were Effortlessly progressing students compared to $61 \%$ of the rapidly progressing humanities students. However, because of the small number of participants, particularly those studying law, these differences need to be analysed with caution.

\section{Discussion}

The aim of the study was to explore the individual study profiles of successful university students. Our assumption was that even though this rapidly progressing group seemed homogeneous in terms of study progress and success at the group level, the students would differ in study practices, processes and experiences. An abductive analysis method was 
selected, because we aimed at generating new theoretical insights on the factors contributing to successful studying at the individual level.

The rapidly progressing students were categorised into two profiles. One third were placed in the Strenuously progressing students profile. Despite all overt signs of smooth progress and successful studying - such as a high number of credits, no missed deadlines or failed exams - these students felt strained and had found time management and the independent nature of university studying to be challenging. Good study success combined with being strained and anxious can be considered as implying a defensive pessimism cognitive strategy, which has been shown to be an effective way to motivate students to perform and cope with study-related stress better (Cantor and Norem 1989; Martin et al.2003). Two thirds of the rapidly progressing students had progressed effortlessly without difficulties regarding workload or stress. The study progress and study experiences of Effortlessly progressing students' first university year can be characterised by lightness' and 'brightness', typical of an optimistic strategy (e.g. Heikkilä et al. 2012; Nurmi et al. 2003). These students reported no study-related anxiety, which is in line with Rothblum et al. (1986) who showed that students with no signs of procrastination (in other words, voluntary delay of study activities despite potential negative consequences; Klingsieck 2013) exhibited very little anxiety compared to procrastinators who scored high, particularly on test anxiety. Also in line with Rothblum et al. (1986) was that these students attributed success in exams to their own ability and effort, while procrastinators have been shown to attribute success to external factors (Authors 2015a; Rothblum et al. 1986).

The rapidly progressing students were easily categorised into the two progress profiles with one exception: one 'fast' student who mostly exhibited the characteristics and experiences of Strenuously progressing students but also elements of procrastination, particularly 
unnecessary delay and clear difficulty with time management and self-regulation (Authors 2015a).

Contrary to our assumption, we found no differences between the two profiles regarding student motivation, interest, self-efficacy beliefs and volition. All students showed high intrinsic motivation to study, personal interest in their disciplines, and a strong volitional mind-set. This is in line with studies showing that students' motivation and interest in studying are related to study progress and success (e.g. Entwistle 2009; Heikkilä et al. 2012; Pintrich 2004). The rapidly progressing students also seemed to be able to use volitional processes successfully to reach their objectives, as was shown by Dewitte and Lens (2000).

Furthermore, we found some variation in the use of a deep approach. All students aimed at achieving understanding and constructing meaning. However, Strenuously progressing students did not always succeed in applying a deep approach whereas Effortlessly progressing students showed evidence of systematically using it. This prevalence of a deep approach to learning is in line with previous research showing that students' approaches to learning are related to study success (e.g. Amirali et al. 2004; Román et al. 2008) and to academic progress (Duff 2004; Lindblom-Ylänne and Lonka 1999). A combination of intrinsic motivation, personal interest, volitional mind-set and a deep approach to learning indicates a strong disposition to understand for oneself (Entwistle and McCune 2013).

Even though the students in both profiles showed good self-regulation skills and strong self-efficacy for self-regulation, Effortlessly progressing students had better self-regulation and time-management skills. Moreover, Effortlessly progressing students showed stronger selfefficacy for self-regulation (Klassen et al. 2008). They also described the most positive study experiences and expressed the most optimism regarding their forthcoming studies and future careers. According to Alexander and Onwuegbuzie (2007), a high level of hope or optimism reduces the probability of procrastination. This is in line with our results, in that a positive 
attitude to studying and expectations of success were evident in both progress profiles, but even stronger among Effortlessly progressing students.

Further, the results can be interpreted in the light of previous evidence concerning the complex relationship between self-efficacy beliefs and experiences of being challenged and threatened (Authors 2015a; Meijen et al. 2013): Strenuously progressing students showed strong self-efficacy beliefs, and had experienced studying as challenging, but did not experience their study situation as threatening compared to procrastinating students, who have been shown to suffer from weaker self-efficacy beliefs and who often experience their study situation as both challenging and threatening (Authors 2015a). Furthermore, compared to rapidly progressing students, slowly progressing students are more likely to experience negative feelings related to their studying and learning, such as worry, anxiety, confusion and a sense of incompetence. Rapidly progressing students are likely to experience more positive feelings, such as enthusiasm, and a sense of both competence and satisfaction. Interestingly, however, some rapidly progressing students have been shown to experience strong negative emotions such as anxiety and frustration (Authors 2015b). These students resemble the Strenuously progressing students identified in the present study.

Also of interest, the law and humanities students were unevenly divided in the two profiles: all but two law students belonged to the Effortlessly progressing students profile compared to $61 \%$ of the humanities students. These discrepancies probably cannot be explained by disciplinary differences, but instead indicate that situational factors play an important role in facilitating study progress. The law and humanities curricula are different in nature: the first consists largely of mandatory legal courses and leaves little freedom of choice, whereas humanities students must make their own decisions concerning their minors. Thus the results suggest that having the freedom to choose between numerous possibilities may present challenges to study progress (see also Authors 2015a). The over-representation 
of humanities students in the Strenuously progressing students profile shows that study progress involves more challenges in a curriculum where students have more options and more freedom of choice. However, it must be kept in mind that the data were rather small and represented only two disciplines.

The present research deepens our understanding of the diversity of individual study paths in the first university year, and of the complex interplay between motivational, volitional and situational factors contributing to study progress. In endeavouring to support students' study processes we should bear in mind that successful, rapidly progressing students might also face challenges and experience difficulties in their studying.

\section{References}

Authors, 2015a

Authors, 2015b

Alexander, E., \& Onwuegbuzie, A. (2007). Academic procrastination and the role of hope as a coping strategy. Personality and Individual Differences, 42, 1301-1310.

Amirali, M., Huon, G., \& Kevin, B. (2004). Approaches to studying and academic performance in short-essay exams. Higher Education, 47, 161-176.

Asikainen, H., Parpala, A., Virtanen, V., \& Lindblom-Ylänne, S. (2013). The relationship between student learning process, study success and the nature of assessment. A qualitative study. Studies in Educational Evaluation, 39, 211-217. 
Biggs, J. (1979). Individual differences in study processes and the quality of learning outcomes. Higher Education, 8, 381-394.

Cantor, N. \& Norem, J. (1989). Defensive pessimism and stress and coping. Social Cognition, 7, $92-112$.

Cheng, P.Y., \& Chiou, W.-B. (2010). Achievement, attributions, self-efficacy, and goal setting by accounting undergraduates. Psychological Reports, 106(1), 1-11.

Dewitte, S., \& Lens, W. (2000). Exploring volitional problems in academic procrastinators. International Journal of Educational Research, 33, 733-750-

Duff, A. (2004). Understanding academic performance and progression of first-year accounting and business economics graduates: The role of approaches to learning and prior academic achievement. Accounting Education, 13, 409-430.

Entwistle, N.J. (2009). Teaching for Understanding at University: Deep Approaches and Distinctive Ways of Thinking. Basingstoke, Hampshire: Palgrave Macmillan.

Entwistle, N., \& McCune, V. (2004). "The conceptual base of study strategies inventories in higher education." Educational Psychology Review, 16, 325-345.

Entwistle, N. \& McCune, V. (2013). The disposition to understand for oneself at university. Integrating learning processes with motivation and metacognition. British Journal of Educational Psychology, 83, 267-279.

Entwistle, N., \& Ramsden, P. (1983). Understanding student learning. London: Croom Helm.

Eronen, S., Nurmi, J-E., \& Salmela-Aro, K. (1998). Optimistic, defensive-pessimistic, impulsive and self-handicapping strategies in university environments. Learning and Instruction, 8(2), 159-177.

Gale, T. \& Parker, S. (2014). Navigating change: a typology of student transitions in Australian higher education. Studies in Higher Education 39(5), 734-753.

Heikkilä, A., \& Lonka K. (2006). Studying in higher education: students' approaches to 
learning, self-regulation, and cognitive strategies. Studies in Higher Education, 31(1), 99-117.

Heikkilä, A., Lonka, K., Nieminen, J., \& Niemivirta, M. (2012). Relations between teacher students' approaches to learning, cognitive and attributional strategies, well-being, and study success. Higher Education, 64, 455-471.

Hidi, S., \& Renninger, K.A. (2006). The Four-Phase Model of Interest Development. Educational

Psychologist, 41, 111-127.

Jones, E. \& Berglas, S. (1978). Control of attributions about the self through selfhandicapping strategies: the appeal of alcohol and the role of underachievement. Personality and Social Psychology Bulletin, 4(2), 200-206.

Klassen, M., Krawchuk, L., \& Rajani, S. (2008). Academic procrastination of undergraduates: Low self-efficacy to self-regulate predicts higher levels of procrastination. Contemporary Educational Psychology, 33, 915-931.

Klingsieck, K. (2013). Procrastination. When good things don't come to those who wait. European Psychologist, 18(1), 24-34.

Krapp, A. (2005). Basic needs and the development of interest and intrinsic motivational orientations. Learning and Instruction 15, 381-395.

Krapp, A. (2002). Structural and dynamic aspects of interest development: theoretical considerations from an ontogenetic perspective. Learning and Instruction, 12, 383-409. Lindblom-Ylänne, S. (2004). Raising students' awareness of their approaches to study. Innovations in Education and Teaching International, 41 (4), 405-422.

Lindblom-Ylänne, S., \& Lonka, K. (1999). "Individual ways of interacting with the learning environment - are they related to study success?" Learning and Instruction, 9, 1-18.

Martin, A., Marsh, H., \& Debus, R. (2003). Self-handicapping and defensive pessimism: A model 
of self-protection from a longitudinal perspective. Contemporary Educational Psychology,

$2, .1-36$

Marton, F., \& Säljö, R. (1997). Approaches to learning. In F. Marton, D. Hounsell \& N. Entwistle (Eds.), The experience of learning. implications for teaching and studying in higher education (2nd ed., pp. 39-59). Edinburg: Scottish Academic Press.

Mikkonen, J., Heikkilä,, A., Ruohoniemi, M. \& Lindblom-Ylänne, S. (2009). "I study because I'm interested" University students' explanations for their educational choices. Scandinavian Journal of Educational Research, 53(3), 229-244.

Meijen, C., Jones, M., McCarthy, P., Sheffield, D., \& Allen, M. (2013). Cognitive and affective components of challenge and threat states. Journal of Sports Sciences, 31(8), 847-855.

Mikkonen, J., \& Ruohoniemi M. (2011). How do veterinary students' motivation and study practices related to academic success? Journal of Veterinary Education, 38, 298-304.

Norem, J., \& Cantor, N. (1986). Defensive pessimism: Harnessing anxiety as motivation. Journal of Personality and Social Psychology, 51(6), 1208-1217.

Nurmi, J.-E., Aunola, K. Salmela-Aro, K., \& Lindroos, M. The role of success expectation and task-avoidance in academic performance and satisfaction: Three studies on antecedents, consequences and correlates. Contemporary Educational Psychology, 28, 59-90.

Parpala, A., Lindblom-Ylänne, S.,Komulainen, E., Litmanen, T. \& Hirsto, L. (2010). Students' approaches to learning and their experiences of the teaching-learning environment in different disciplines. British Journal of Educational Psychology, 80(2) , 269-282.

Pintrich, P. R. (2004). A conceptual framework for assessing motivation and self-regulated learning in college students. Educational Psychology Review, 16(4), 385-407. 
Román, S., Cuestas, P., \& Fenollar, P. (2008). An examination of the interrelationships between self-esteem, others' expectations, family support, learning approaches and academic achievement. Studies in Higher Education 33, 127-138.

Rothblum, E., Solomon, L., \& Murakami, J. (1986). Affective, cognitive and behavioural differences between high and low procrastinators. Journal of Counseling Psychology, 33(4), 387-394.

Rytkönen, H., Parpala, A., Lindblom-Ylänne, S., \& Postareff, L. (2012). Factors influencing bioscience students' academic achievement. Instructional Science, 40, 241-256.

Segers, M., Dochy, F., \& Cascallar, E. (Eds.) (2003). Optimising new modes of assessment: in search of qualities and standards. Dordrecht, The Netherlands: Kluwer Academic Publishers.

Struyven, K., Dochy, F., \& Janssens, S. (2005). Students' perceptions about evaluation and assessment in higher education: a review. Assessment \& Evaluation in Higher Education, $30,325-341$.

Timmermans, S., \& tavory, I. (2012). Theory construction in qualitative research: From grounded theory to abductive analysis. Sociological Theory, 30 (3), 167-186.

Trigwell, K., Ellis, R. A., \& Han, F. (2012). Relations between students' approaches to learning, experienced emotions and outcomes of learning. Studies in Higher Education, 37, 811824.

Vermunt, J.D. (2005). Relations between student learning patterns and personal and contextual factors and academic performance. Higher Education, 49, 205-234. 